\title{
Improved performance of strained InGaAs/GaAs photodiodes grown on patterned GaAs substrates by molecular beam epitaxy
}

\author{
W. Q. Li and P. K. Bhattacharya \\ Electrical Engineering and Computer Science, The University of Michigan, \\ Ann Arbor, Michigan, 48109-2122 \\ R. L. Tober \\ Harry Diamond Laboratories, Adelphi, Maryland 20783-1145
}

Solid State Electronics Iaboratory and Center for High Frequency Microelectronics Department of

(Received 19 November 1990; accepted for publication 5 February 1991)

\begin{abstract}
We have experimentally studied the photoresponse characteristics of strained $\operatorname{In}_{x} \mathrm{Ga}_{1}{ }_{x} \mathrm{As}$
$(0.05 \leqslant x \leqslant 0.20) p-i-n$ photodiodes grown in small holes etched in GaAs substrates

where the thickness of the $i$ region exceeds the critical thickness. The diodes exhibit enhanced

quantum efficiency and no degradation of the temporal response compared with devices

grown on planar substrates, indicating that reduced area growth may be a useful technique for

making optoelectronic devices with strained-layer structures.
\end{abstract}

There has recently been a burgeoning interest in epitaxial and heteroepitaxial growth of semiconductors on patterned substrates. ${ }^{1-4}$ In addition to the need to understand the fundamental growth mechanism and growth modes, interest in the growth on patterned substrates has increased for its application in three principal areas. First, it has been demonstrated that pseudomorphic InGaAs/ $\mathrm{GaAs}$ lasers with very low threshold currents ${ }^{2}$ and lasers with lower dimensional confinement in the active region ${ }^{3}$ can be achieved by growth on patterned substrates. Second, the higher index planes obtained by etching provide the possibility of preferential doping depending on the bonding configuration on the surface. For example it is possible to incorporate $\mathrm{Si}$, an amphoteric dopant in most III-V compounds, preferentially in donor or acceptor sites. $^{4}$ Finally, it has been proposed ${ }^{5}$ and demonstrated ${ }^{6}$ that epitaxial growth on finite substrates can dramatically reduce the density of misfit dislocations, which arise either from the multiplication of threading dislocations present in the starting substrate ${ }^{6}$ or from the strain relaxation process once the critical thickness is reached during strained-layer epitaxy. ${ }^{7}$ The reduction in dislocation density occurs when growth is done in a hole or on a mesa surface. In the work being reported in this letter, we have exploited this feature to demonstrate improved performance of strained layer InGaAs/GaAs photodiodes grown on a GaAs substrate. This opens up the possibility of achieving band-gap tailoring without being limited by the critical thickness in strained-layer epitaxy.

The starting Si-doped GaAs substrates were cleaned by standard solvent degreasing, a $3 \mathrm{~min}$ etch in $5 \mathrm{H}_{2} \mathrm{SO}_{4}: 1 \mathrm{H}_{2} \mathrm{O}_{2}: 1 \mathrm{H}_{2} \mathrm{O}$, and a final rinse in de-ionized water. They were then patterned using conventional optical lithography and wet chemical etching. Buffered $\mathbf{H F}$ ( $\mathrm{BHF}$ : $: \mathrm{H}_{2} \mathrm{O}_{2}: \mathrm{H}_{2} \mathrm{O}$ with an appropriate concentration ratio was used to achieve a flat and smooth etched surface. Both square and round holes with sizes varying between 30 and $100 \mu \mathrm{m}$ and a depth of $1 \mu \mathrm{m}$ were made on the same substrate. The angle of the side walls in the holes range from $30^{\circ}$ to $55^{\circ}$ depending on etch composition. Growth in holes instead of mesas is preferred since the active epitaxial structures "fill out" the holes and after etching away the epilayer on the surrounding substrate, a planar surface suitable for planar processing is preserved. After patterning, the wafers were again rinsed in organic solvents and free etched for $1 \mathrm{~min}$ in 3BHF: $1 \mathrm{H}_{2} \mathrm{O}_{2}: 1 \mathrm{H}_{2} \mathrm{O}$ before loading into the growth chamber of a molecular beam epitaxy (MBE) system. A nonpatterned substrate is also mounted along side in order to monitor the surface oxide desorption and to compare the performance of devices on it with those in the holes of the patterned substrates.

Figure 1(a) is a schematic of the device heterostructure. The thickness of the undoped $\operatorname{In}_{x} \mathrm{Ga}_{1-x}$ As layer of the photodiode was chosen to exceed critical thickness. For our experiments, structures with $x=0.05,0.10,0.15$, and 0.20 were grown. Growth at $600{ }^{\circ} \mathrm{C}$ was commenced on (100) $n^{+}$-GaAs substrates with a few periods of GaAs/ $\mathrm{Al}_{0.3} \mathrm{Ga}_{0.7} \mathrm{As}$ smoothing superlattice, followed by the 0.3 $\mu \mathrm{m}$ Si-doped $\left(n=1 \times 10^{18} \mathrm{~cm}^{-3}\right) \mathrm{GaAs}$ contact layer. This was followed by growth of the $0.7 \mu \mathrm{m}$ strained undoped $\operatorname{In}_{x} \mathrm{Ga}_{1-x} \mathrm{As}$ layer at $500^{\circ} \mathrm{C}$ and 400 - $\AA$-thick Bedoped $\left(p=5 \times 10^{18} \mathrm{~cm}^{-3}\right) \operatorname{In}_{x} \mathrm{Ga}_{1-x}$ As layer at the same temperature. After growth, the samples were examined with a Nomarski dark field microscope. For low In content in the diode layers $(x<0.10)$, a smooth, featureless surface was obtained on both the patterned and planar substrates. For higher In compositions, a cross-hatched pattern was seen on the surface, indicating the presence of interfacial misfit dislocations, ${ }^{6}$ since the strained-layer thickness far exceeds the nominal critical thickness in each case.

Piezoreflectance measurements were made at $77 \mathrm{~K}$ to determine the band gap of the patterned and control samples. The results are shown in Figs. 2(a) and 2(b). The peaks correspond to the band gaps. It is evident that there is no change of band gap in the patterned samples, indicating the absence of metastable growth. This is important for device performance.

To fabricate the $p-i-n$ diodes on the patterned substrates, the grown structure was selectively etched away except in the holes, thereby also forming the isolation mesa. The bottom ohmic contact to the $n^{+}-$GaAs substrate was made by evaporating $\mathrm{Ge} / \mathrm{Ni} / \mathrm{Ti} / \mathrm{Au}$ and ther- 


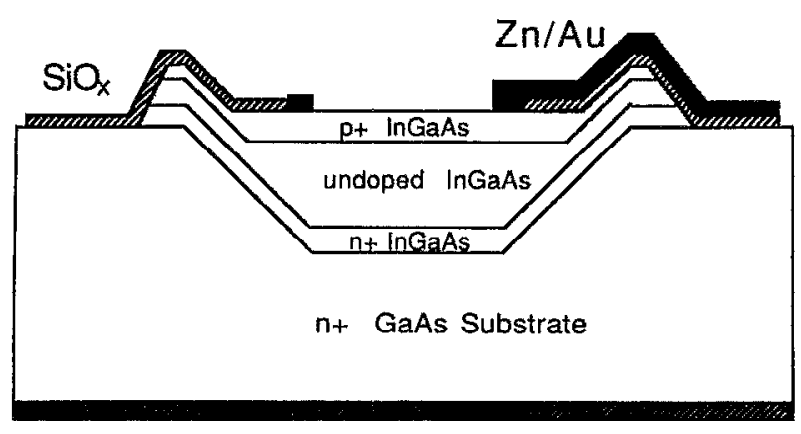

$\mathrm{Ti} / \mathrm{Au}$

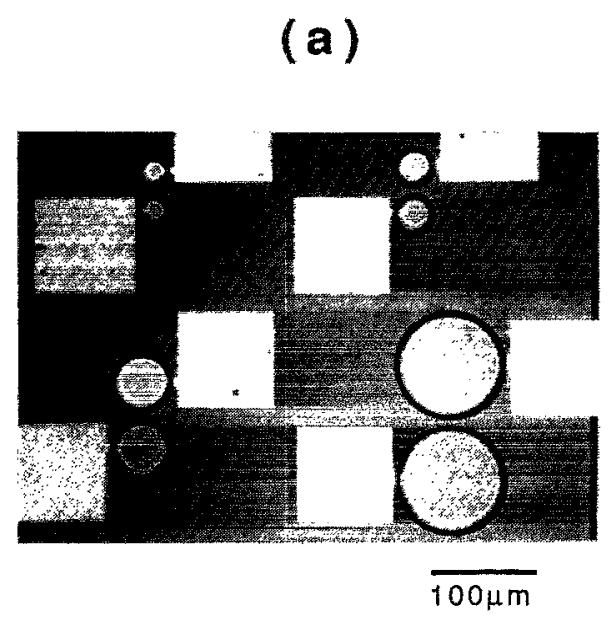

(b)

FIG. 1. (a) Schematic of the strained $\operatorname{In}_{x} \mathrm{Ga}_{1-x} \mathrm{As} / \mathrm{GaAs} p-i-n$ diode grown in an etched hole on $n^{+}$-GaAs substrate, (b) microphotograph of fabricated photodiodes of different dimensions.

mal annealing. Top annular ring contacts on $p^{+}-\mathrm{GaAs}$ were formed by $\mathrm{Zn} / \mathrm{Au}$ evaporation and standard lift-off technique. Finally, a thick $\mathrm{SiO}_{2}$ layer was deposited by plasma-enhanced chemical vapor deposition (PECVD) and bonding pads were formed for the top contacts through openings selectively etched in the $\mathrm{SiO}_{2}$. The same fabrication procedure was followed to make the photodiodes on the planar monitor samples. The completed devices are shown in Fig. 1(b). The photodiodes made on both planar and patterned substrates exhibit very low dark current densities $\left(\sim 50 \mu \mathrm{A} / \mathrm{cm}^{2}\right)$ and an average breakdown voltage of $12 \mathrm{~V}$. To measure the external quantum efficiency and temporal responsc of the diodes, a pulsed dye laser operating at a wavelength of $835 \mathrm{~nm}$ was used as the excitation source. The nominal pulse width is $5 \mathrm{ps}$. The diode was mounted on a high-frequency testing fixture ( 45 $\mathrm{MHz}-26 \mathrm{GHz}$ ) and the dc bias and high-frequency response were separated through a bias-tee network. The temporal response was recorded on a synchronized oscilloscope. The results obtained from $50-\mu \mathrm{m}$-diam devices with different indium compositions, both within the patterned holes and on the planar subsirates, are shown in Fig. 3. During measurement, care has been taken to focus

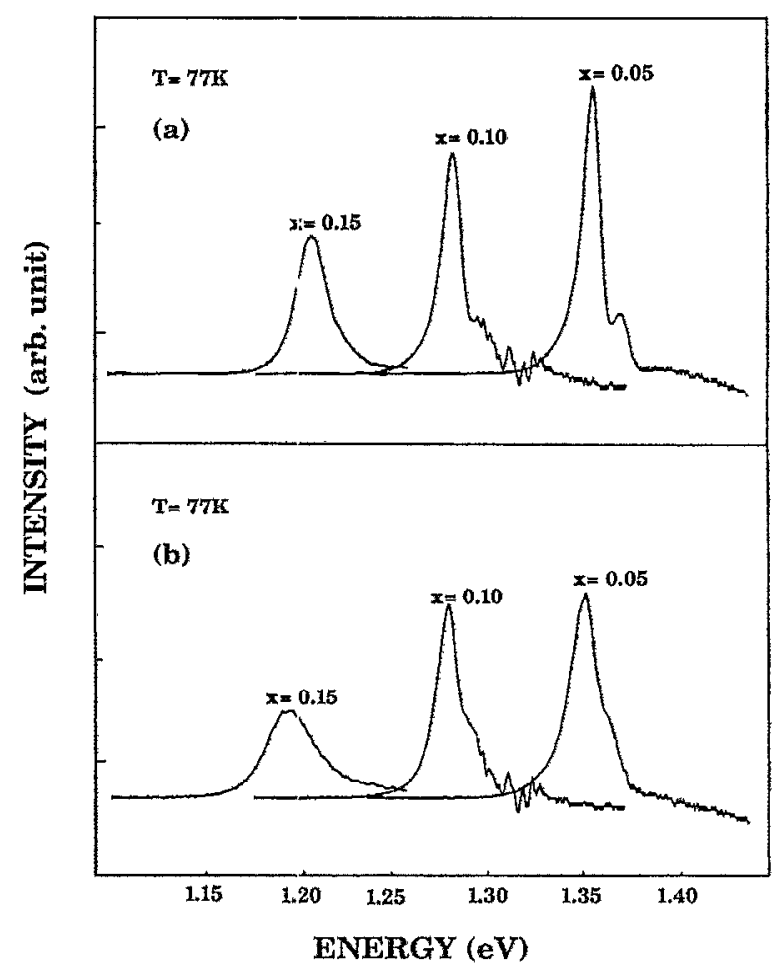

FIG. 2. Piezoreflectance spectra of $\mathrm{In}_{x} \mathrm{Ga}_{1}{ }_{x} \mathrm{As}$ photodiode layers grown on GaAs substrates: (a) planar control samples, and (b) patterned samples.

the incident optical beam to a size smaller than the device area and to maintain the incident optical power density constant. We believe that the observed temporal response time is mainly limited by the parasitic capacitance associated with the bonding pads on the conducting substrate. High-speed lattice-natched photodiodes of similar dimensions on semi-insulating substrates have response times a factor of two smaller. It is more important to note that the temporal response of the diodes in the holes is comparable to that of diodes grown on the planar substrates and the fall time is actually shorter. Furthermore, the photoresponse amplitude of the diodes grown in holes is higher than that of the planar diodes by a factor of 2-4. This number was obtained by comparing two groups of strained $\mathrm{In}_{x} \mathrm{Ga}_{1-x} \mathrm{As} / \mathrm{GaAs} p-i-n$ diodes which were grown on planar and patterned substrates under identical conditions. The indium compositions in these samples varied from $x=0.05$ to $x=0.20$, and the diodes ranged in diameter from 30 to $100 \mu \mathrm{m}$. The largest difference in responsivity between the devices on patterned substrates and that on planar substrates was observed in samples with $x=0.20$, as indicated in Fig. 3(b). The corresponding responsivity is $\sim 0.3 \mathrm{~A} / \mathrm{W}$, obtained with a calibrated $\mathrm{Si}$ photodiode. The photoresponse amplitude is directly proportional to the quantum efficiency. Since the quantum efficiency of a $p-i-n$ diode is critically dependent on the carrier lifetime in the active region limited by defects and recombination centers, the enhanced photoresponse of the diodes grown in small holes indicates that the misfit dislocation density is 


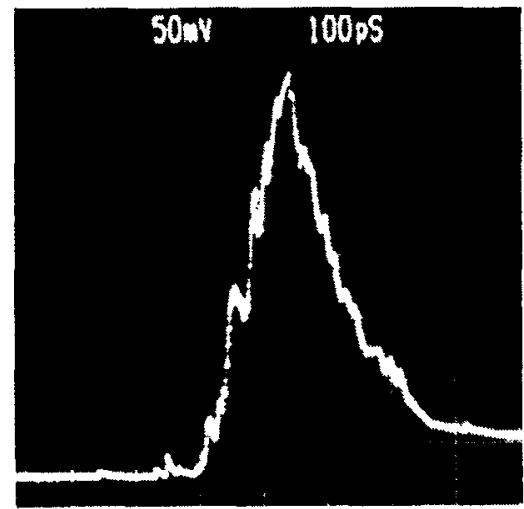

planar

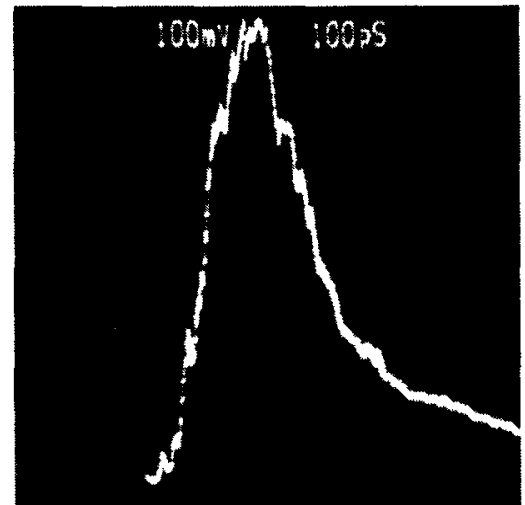

patterned

\section{(a)}

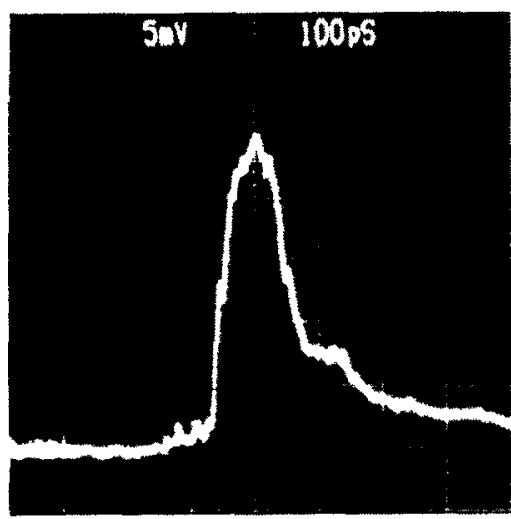

planar

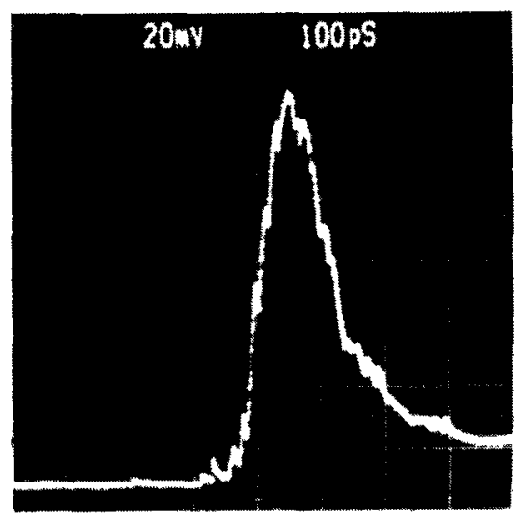

patterned
FIG. 3. Temporal response of the strained $\operatorname{In}_{x} \mathrm{Ga}_{1}{ }_{x} \mathrm{As} / \mathrm{GaAs} p-i-n$ diodes to pulsed dye laser excitation with pulse full width at half maximum (FWHM) of 5 ps: (a) $x=0.10$, and (b) $x=0.20$. smaller in these devices than that in devices grown on planar substrates. Our results indicate that reduced area growth is a promising technique to improve strained epitaxial layer quality as well as optoelectronic device performance. Use of this technique to realize strained-layer photodiode arrays appears to be promising.

In conclusion, we have experimentally studied the photoresponse of strained InGaAs $p-i-n$ photodiodes grown in small holes etched in GaAs substrates. The enhanced quantum efficiency of these diodes and no degradation of the temporal response compared with those grown on planar substrates indicate that reduced area growth is a useful technique for making optoelectronic devices with strainedlayer structures. Thus the full versatility of band-gap tai- loring can be exploited.

The work is supported by the Army Research Office (University Research Initiative program) under contract DAAL-03-86K0105.

'E. Kapon, M. C. Tamargo, and D. M. Hwang, Appl. Phys. Lett. 48, 347 (1987).

${ }^{2}$ H. Jaeckel, H. P. Meier, G. L. Bona, W. Walter, D. J. Webb, and E. van Gieson Appl. Phys. Lett. 55, 1059 (1989).

${ }^{3}$ E. Kapon, D. M. Hwang, and R. Bhat, Phys. Rev. Lett. 63, 430 (1989).

${ }^{4}$ H. P. Meier, R. F. Broom, P. W. Epperlein, E. van Gieson, Ch. Harder, H. Jaeckel, W. Walter, and D. J. Well, J. Vac. Sci. Technol. B 6, 692 (1988).

5J. W. Mathew, S. Mader, and T. B. Light, Appl. Phys. Lett. 41, 3800 (1970).

${ }^{6}$ E. A. Fitzgerald, G. P. Watson, R. E. Proano, D. G. Ast, P. D. Kirchner, G. D. Pettit, and J. M. Woodall, J. Appl. Phys. 65, 2220 (1989). ${ }^{7}$ S. V. Ghaisas and A. Madhukar, J. Vac. Sci. Technol. B 7, 264 (1989). 